\title{
TRANSLATION
}

DOI:

\section{DENOTATIVE AND TRANSFORMATIONAL APPROACHES TO THE TRANSLATION OF IDIOMS FROM ENGLISH INTO RUSSIAN}

\author{
Galina Bezkorovaynaya \\ PHD in Philology, Assistant Professor \\ Moscow Polytechnical University, Higher School of Printing and Media Industry \\ (Moscow, Russia) \\ e-mail: begati1@yandex.ru
}

\begin{abstract}
The phraseoligisms and idioms are one of the expressive means of the language and speech. The aim of this article is to regard denotative and transformational methods exemplified by the translation of the novel Pelham (1828) by Edward George Bulwer Lytton (1803-1873) and its Russian translation by A.S. Kulisher, N.Y.Rikova (1958). Based on the examples of the novel text the phraseologisms of the original and translation into Russian are analyzed. The denotative approach to the translation is the main one here and it is based on the general writer's concept. The translators use the phraseologisms where there are not any idioms in the original. Sometimes they use them instead of phrasal verbs.
\end{abstract}

Key words: phraseologism, denotative translation, transformation, writer's language, fiction text

\section{ДЕНОТАТИВНЫЙ И ТРАНСФОРМАЦИОННЫЙ ПОДХОДЫ К ПЕРЕВОДУ ФРАЗЕОЛОГИЗМОВ С АНГЛИЙСКОГО ЯЗЫКА НА РУССКИЙ}

\author{
Галина Тиграновна Безкоровайная \\ Кандидат филологических наук, доцент \\ Московский политехнический университет \\ Высшая школа печати и медиаиндустрии \\ (Москва, Россия) \\ e-mail: begati1@yandex.ru
}

\begin{abstract}
Аннотация: Фразеологизмы являются одни из эмоционально-экспрессивных ресурсов языка. Предметом данной статьи является рассмотрение денотативного и трансформационного подхода к переводу фразеологизмов с английского на русский. В качестве примера выбран роман Эдуарда Джорджа Бульвер-Литтона (Edward George Bulwer Lytton, 1803-1873) "Pelham"(1828) и его перевод, выполненный А.С.Кулишер и Н.Я. Рыковой «Пелэм, или Приключения джентльмена» (1958). В статье анализируются примеры перевода разных разрядов фразеологизмов на русский язык. Основной подход к переводу данного произведения - денотативный, т.е. исходящий из общего сюжета и стиля писателя. Фразеологизмы иногда появляются в русском переводе там, где они отсутствуют в английском тексте, либо таким образом передаются фразовые глаголы.
\end{abstract}

Ключевье слова: фразеологические единицы, денотативный перевод, переводческая трансформация, язык писателя, художественный текст

\section{ORCID https://orcid.org/0000-0003-0088-3619}

ВВЕДЕНИЕ. Изучение двух подходов к переводу фразеологизмов в данной статье - денотативного и трансформационного - основано на анализе конкретного произведения Эдуарда Джорджа Бульвер-Литтона (Edward George Bulwer Lytton, 1803-1873) «Pelham» (в русской версии - «Пелэм, или Приключения джентльмена») (1828). В центре внимания находятся фразеологизмы разных разрядов: идиомы, паремии, крылатые выражения - и их перевод на русский язык.

Роман пользовался большим успехом в Европе, а в России им восхищался А. С. Пушкин, который имел замысел написать роман «Русский Пелам» (сохранилось несколько развёрнутых планов). Жизнь юного аристократа-денди, щёголя и завсегдатая великосветских салонов и игорных домов Пелэма находится в центре повествования от первого лица. Роман и, прежде всего, фигура главного героя были задуманы автором, чтобы показать, как человек, внутренне не зависимый, способен избежать дурного влияния света (Matveenko 2003). В романе переплетены две сюжетные линии. В одной из них Пелэм всеми силами стремится достичь высокого положения в обществе путём любовных связей, участием в грязных политических играх, стремлением выгодно жениться. Другая, детективная, описывает трагедию Реджинальда Гленвила - университетского друга Пелэма его месть обидчику своей возлюбленной при помощи различных проходимцев, убийство и связанное с ним расследование (Matveenko 2003). 
ОБЗОР ЛИТЕРАТУРЫ. Хотя вопросы перевода фразеологизмов с одного языка на другой привлекают внимание многих лингвистов, основополагающими по сей день являются работы А.В. Кунина - автора и составителя «Большого англо-русского фразеологического словаря», разработчика теории фразеологии английского языка . В предисловии к нему лингвист отмечает особую сложность перевода фразеологизмов, подчеркивая, что « при переводе устойчивых сочетаний слов следует также учитывать особенности контекста, в котором они употребляются» (Кunin 1967: 4). Мастера переводоведения отмечают различия переводческих подходов и приемов, в том числе при передаче значений фразеологизмов. Достаточно упомянуть известные теории А.Д. Швейцера, Я.И. Рецкера, Л.С. Бархударова.

Определение трансформационного и денотативного подхода разнятся. Так, А.М. Фитерман и Т.Р. Левицкая определяют три типа трансформаций: грамматические, стилистические, лексические трансформации. Сюда входят замена и добавление, конкретизация, генерализация предложений, опущение. А.Д. Швейцер, рассуждая об уровнях, позволяющих применять трансформации, предлагает делить трансформации на четыре группы, при этом считает, что на стилистическом уровне могут иметь место как грамматические, так и лексические трансформации. Я.И. Рецкер, напротив, называет лишь два типа трансформаций. Этот лингвист говорит о таких приемах их воплощения, как грамматические трансформации в виде замены частей речи или членов предложения, лексические трансформации заключаются в конкретизации, генерализации, дифференциации значений, антонимическом переводе, компенсации потерь, возникающих в процессе перевода, а также в смысловом развитии и целостном преобразовании. Нет единства и в определении денотативного приема перевода. Денотативная теория перевода определяет перевод как процесс описания при помощи языка перевода денотатов, описанных на языке оригинала. «Воспринимая текст оригинала, переводчик отождествляет составляющие этот текст единицы с известными ему знаками исходного языка и через эти последние выясняет, какую ситуацию реальной действительности описывает оригинал. (Rarenko, 2010; 31-32). Уделяется внимание в лингвистике и особенностям перевода фразеологизмов в художественных текстах. В последние годы появились работы по этой тематике (см., например: Kazakova 2006; Sdobnikov, Petrova 2001) .

Вопросами различных подходов к переводу художественных произведений занимаются и зарубежные лингвисты (Landers, 2001; Snell-Hornby, 2006). Набор лексико-фразеологических средств, помогающих говорящему / пишущему представить фразеологическое значение или его смысловые нюансы, а также реализация их значений происходит в рамках фразеоконтекста. В фразеосеминаре профессора В.М. Мокиенко также большое внимание уделено этой проблеме (Mokienko 2003). Вместе с тем остается ряд вопросов, которые не изучены в достаточной степени, в том числе и применение обеих стратегий в переводе фразеологизмов.

МЕТОДЫ ИССЛЕДОВАНИЯ. Основным методом проведённого исследования был избран сравнительносопоставительный, предусматривающий анализ отобранных приемом сплошной выборки примеров фразеологизмов в оригинале и переводе изучаемого текста романа. С целью определения использованных в переводе на русский приемов и подходов применялся семантический анализ лексических единиц и фразеологизмов. Применялся также метод анализа переводческих решений.

РЕЗУЛЬТАТЫ И ДИСКУССИЯ. Проведенное исследование предполагало отбор и анализ фрезеологизмов языка оригинала и перевода романа «Pelham» («Пелэм, или Приключения джентльмена»). Особенности стиля романа «Пэлем» рассматривались исследователями. «Многообразие лексики и фразеологии романа вызвано сочетанием легкого великосветского юмора и серьезной, то задушевной, то резонерской, то насыщенной мыслями беседы, реалистического описания улиц и зданий Парижа с готической романтикой кладбища в ночных скитаниях героев» (Chicherin 1958, XV).

Над переводом романа трудились А. С. Кулишер (главы I-LIV) и Н. Я. Рыковой (предисловия и главы LV-LXXXVI). Обе переводчицы принадлежали к ленинградской школе переводо. Они особенно известны переводами с немецкого и французского языков. В списке работ А.С. Кушнер роман Бульвера-Литона чуть ли не единственный с английского.

Анализ отобранных при исследовании примеров показал, что в тексте романа присутствуют различные по составу фразеологические ресурсы: паремии, библеизмы, идиомы. Вместе с тем в тексте оригинала и в переводном тексте их количество разнится.

Повествование ведется от первого лица. Автор, будучи образованным человеком, наполняет текст библеизмами и крылатыми выражениями She keeps a tolerable table, haunted with Poles, Russians, Austrians, and idle Frenchmen, при этом некоторые даны Бульвер-Литтоном на французском или латыни, например: peregrinae gentis amaenum hospitium. Nobilis ornatur lauro collega secundo Le sentiment de nos forces les augmente и т.п.

В тексте романа зачастую такого рода фразеологизмы остаются без перевода, что вполне обоснованно стремлением показать высокую образованность и автора, и главного героя. Иногда библеизмы или цитаты переводятся: отделить зерно от плевел - ad separatum triticum a paleis.

Фразеологизмы в романе разнообразны по составу и функциям. Как верно отмечает О.В. Ломакина, «при изучении языка писателя особый интерес вызывают различные индивидуально-авторские приёмы использования фразеологических ресурсов языка» (Lomakina 2015, 8). Очевидно, что фразеологизмы, которые использованы в переводе данного романа, учитывают общую тональность стиля Бульвер-Литтона, особенности описания автором современного ему общества. Автор использует пословицы, которые сохранены в переводе: 'a ram may kill a butcher.- A знаете, ведь «иной раз бывает, что баран мясника зашибает».Stultitiam paliuntur, ореs-Богатство покрывает глупость.

Наличие соответствующего эквивалента позволяет дать в русском переводе адекватный вариант пословицы, библеизма и т.п. В русском переводе встречаем разговорно-просторечные фразеологизмы. Например: 
Пропустив это замечание, мимо ушей; накормить вас до отвала; Меня словно окатили ушатом ледяной водыл; первой мне попалась на глаза пусть пеняет на свое собственное безрассудство - Пенять на себя; они ей нужны до зарезу; попадалось мне на глаза, При сопоставлении примеров видно, что в переводе возникают фразеологизмы, а в оригинале их нет: Several days passed. I had taken particular pains to ingratiate myself with Lady Roseville (ch. VI). Прошло несколько дней; я всячески старался приобрести расположение леди Розвил, и в той мере, в какой дело касалось банального светского общения (гл. VI). I recovered myself instantly (ch. VI). $\boldsymbol{Я}$ мгновенно пришел в себя (гл. VI); had utterly disappeared. (ch. VII) сnустя минуту бесследно исчез Glanville shook me from him in an instant, covered his face with his hands, and sunk down with one wild cry, which went fearfully through that still place, upon the spot from which he had but just risen. В мгновение ока Гленвил оттолкнул меня, закрыл лицо руками, издал нечеловеческий стон, жутко прозвучавший в безмолвии кладбища, - и рухнул наземь у той могиль, с которой только что поднялся (гл. VI). The reply came upon me like a shower bath; I was both chilled and stunned by so unexpected a shock (ch. VII). Меня словно окатили ушатом ледяной воды (гл. VII). Неожиданность ошеломила меня, и в то же время я весь похолодел. I could not sleep the whole of that night, and the next morning (ch. VII). Я не сомкнул глаз всю ночь и на рассвете отправился в путь (гл. VII).

Денотативный способ получает широкое применение. Учитывается общая тональность произведения. По-видимому, репутация столь популярного произведения и стремление увлечь читателя привела в некоторых случаях к вольностям в тексте перевода. Например: I inquired with very considerable emotion, whether there was not an easier way to return (ch. V) я, не на шутку встревожась, спросил, нет ли другого, более удобного пути (гл. V).

Здесь справедливо вспомнить слова К.И. Чуковского о том, что для читателя важно, чтобы были переданы не только внешние формальные качества, но и внутреннее обаяние подлинника. (Чуковский, 1987 , 34). И, хотя эти слова писатель относил к поэтическим произведениям, их можно применить к прозе.

В языке оригинала Литтон использует фразовые глаголы, которые в русском переводе предстают в форме фразеологизмов. Это можно рассматривать не как волю переводчика, а как особенности двух языков. Там, где метафоричность передается аналитическими средствами, переводчик оживляет текст фразеологизмами. Представляется, что стилистика всего романа позволяет сделать это. Следует согласиться с тем, что перевод романа на русский язык «показывает попытку соединения двух противоположных тенденций: с одной стороны, стремление переводчика к передаче художественного своеобразия романа, с другой адаптация текста для массового читателя. Последнее зачастую достигалось либо упрощением содержания и формы оригинала, либо его сокращением» (Matveenko 2010).

ЗАКЛЮЧЕНИЕ. Анализ перевода фразеологизмов разных разрядов в романе Пэлем Бульвер-Литтона, выполненного А.Н.Кулишер и Н.Я. Рыковой на русский язык, позволил сделать вывод о том, что при процессе раскодирования текста переводчики, как правило, использовали такие приемы, как полностью совпадающие эквиваленты, вольный перевод, трансформации, денотативный перевод. Использование разговорнопросторечных фразеологизмов в речи главного героя, который происходит из знатного рода, высокообразован, продиктовано попыткой демократизации текста для советского читателя. Денотативный перевод можно понять как желание придать повествованию некую «народность». Появление фразеологизмов в переводе не оказывает негативного влияния на русскоязычного читателя, а, напротив, способствует повышению интереса к прочтению. Некоторые просторечные фразеологизмы выглядят неестественно в устах благородных и образованных персонажей. «Улучшая» стиль Э. Бульвер-Литтона, перевод не искажает основное содержание и лишь придает роману привлекательность для современного русскоязычного читателя. В то же время денотативный подход в некоторой степени отдаляет его от адекватного перевода текста.

\section{LIST OF REFERENCES}

Kazakova T. A. Xudozhestvenny j perevod. Teoriya i praktika: Uchebnik. [Literary translation.Theory and Practice] - SPb.: OOO «In“yazizdat», 2006. - 544 s. - (Special`naya literatura po inostranny`m yazy`ka

Kunin, A.B. Predislovie k anglo-russkomu frazeologicheskomu slovaryu /[Preface to the Russian-English Phraseological Dictionary] A.B. Kunin // Anglo-russkij frazeologicheskij slovar’. Izd. 3-e, ispr., v dvux knigax. M.: Sov. E`nciklopediya, 1967. - T. 1 - S. 3 - 18. Lomakina O.V. Rol` frazeologicheskix aktualizatorov v smy`slovoj realizacii frazeologizmov i poslovicz $\mathrm{v}$ tekste ( na materiale yazy 'ka L.N. Tolstogo)[The Role of Phraseological Actualisators in the Meaning Realization of Phraseological Units and Proverbs in Fiction Texts ( exemplified by Leo Tolstoy Language]// Vestnik CzMO MGU 2015 №2 S. 7-14

Matveenko I. Vospriyatie tvorchestva E`. Bul'vera-Littona v Rossii 1830-1850-x gg. [Reception of works by E.Bulwer-Lytton in Russia in 1830-1850-] Tomsk: Tom. politexn. un-t, 2005. $241 \mathrm{s.}$

Mokienko V.M. Novajarusskajafrazeologija (New Russian phraseology)/. Opole; UniwersytetOpolski: InstytutFilologiiPolskiej2003.

Osnovny`e ponyatiya perevodovedeniya. Terminologicheskij slovar'-spravochnik [The main concepts of translation Theory. Therminology Dictionary] Pod redakciej Rarenko M.B. INION M. 2010 S.31-32

Sdobnikov V.V., Petrova O.V. Teoriya perevoda. [The Theory of Translation] Uchebnik dlya perevodcheskix fakul'tetov $i$ fakul'tetov inostranny`x yazy kov rezhim dostupa : https://www.studmed.ru/sdobnikov-vv-petrova-ov-teoriya-perevoda-uchebnikdlya-perevodcheskih-fakultetov-i-fakultetov-inostrannyh-yazykov $94886 \mathrm{~cd} 64 \mathrm{bd}$.html

Chicherin A.V. «Pe`lem» Bul`ver-Littona predislovie k knige Bul`ver-Litton Pe`lem, ili priklyucheniya dzhentl`mena.[ Pelham by Bulwer-Lytton. Preface to the book Pelham, the adventuries of a gentleman] M.- Xudozhestvennaya literatura,- 1958-S. XV Chukovskij Vy`sokoe iskusstvo [ The High Art] M.: Sovetskij pisatel`1968. S.90

Landers, Clifford E.Literary Translation. A Practical Guide / Clifford E. Landers. - Multilingual Matters LTD, 2001. - 214 p.

Snell-Hornby, Mary.Translation Studies: An Integrated Approach / Mary Snell-Hornby. - revised edition. - John Benjamins Publishing Com 
Bulwer-Lytton E. Pelham. Mode of access: http://www.gutenberg.org/files/7623/7623-h/7623-h.htm

Bul'ver-Litton Pe`lem, ili priklyucheniya dzhentl`mena. [Bulwer-Lytton Pelham, the adventuries of a gentleman ], M.Xudozhestvennaya literatura,- 1958-S. XVhttps://www.litmir.me/br/?b=129463\&p=1

For citation:

Bezkorovaynaya Galina (2019) DENOTATIVE AND TRANSFORMATIONAL APPROACHES TO THE TRANSLATION OF IDIOMS FROM ENGLISH INTO RUSSIAN // International Scientific-Pedagogical Organization of Philologists " WEST-EAST " (ISPOP). Scientific Journal WEST-EAST. Vol 2/1 N1 (October, 2019). pp. 162-165. doi:

Для цитирования:

Безкоровайная Г. Т (2019) ДЕНОТАТИВНЫЙ И ТРАНСФОРМАЦИОННЫЙ ПОДХОДЫ К ПЕРЕВОДУ ФРАЗЕОЛОГИЗМОВ С АНГЛИЙСКОГО ЯЗЫКА НА РУССКИЙ // Internationa 1Scientific-Pedagogical Organization of Philologists “WEST-EAST” (ISPOP) . Scientific Journal WEST-EAST. Vol 1/1 N1 (October, 2019). C. 162-165. doi:

Information about the author: Bezkorovaynaya Galina - Candidate of Philology, Assistant Professor, department of foreign languages Moscow Polytechnic University, High School of Printing and Media Industry

e-mail: begati1@yandex.ru

Информация об авторе: Безкоровайная Галина Тиграновна - кандидат филол. наук, доцент кафедры « Иностранные языки», Московский политехнический университет, Высшая школа печати и медиаиндустрии.

e-mail: begati1@yandex.ru

Manuscript received: 05/27/2019 Accepted for publication: 09/20/2019

DOI:

\title{
LINGUOCULTUROLOGICAL TRANSLATION PECULIARITIES OF DIPLOMATIC CORRESPONDANCE OF FRENCH CONSULATES IN GEORGIA AND TURKEY (middle $19^{\text {th }}$-early20 ${ }^{\text {th }}$ )
}

\author{
Victoria Diasamidze \\ Doctor of Philology, Associate professor \\ Batumi Shota Rustaveli State University \\ (Batumi, Georgia) \\ e-mail: victoria.diasamidze 777
}

\begin{abstract}
The paper deals with the theoretical understanding and linguocultural interpretation from French into Russian of the archival diplomatic correspondence of the consulates of France in Georgia and the Ministries of Foreign Affairs of France and Turkey of the late XIXth-early XXth century. In this paper we analyse lexical, phraseological features and compare standard architectonics of drawing up official and business handwritten correspondence. Compliance with ethical and professional rules and regulations dictates the specific features of the syntax and appeal to the higher and lower officials. When translating into Russian, idioms and equivalents, generally accepted in official business correspondence with maximum preservation of color and features peculiar to the original, were taken into account.
\end{abstract}

Key words: diplomatic correspondence, French diplomacy, correspondence rules, handwritten discourse

\section{ЛИНГВОКУЛЬТУРОЛОГИЧЕСКИЕ ОСОБЕННОСТИ ПЕРЕВОДА ДИПЛОМАТИЧЕСКОЙ ПЕРЕПИСКИ КОНСУЛЬСТВ ФРАНЦИИ В ГРУЗИИ И ТУРЦИИ (сер. ХІХ-нач. ХХ века)}

\author{
Виктория Григорьевна Диасамидзе \\ Кандидат филологических наук, ассоциированный профессор \\ Батумский государственный университет \\ имени Шота Руставели \\ (Батуми, Грузия) \\ e-mail: victoria.diasamidze777@mail.ru
}

\begin{abstract}
Аннотация. Представленная работа посвящена лингвокультурологической интерпретации перевода с французского языка на русский архивной дипломатической переписки консульств Франции в Грузии МИД Франции и Турции конца XIX-начала $\mathrm{XX}$ века. Рассматриваются лексические, фразеологические и другие особенности, сравнивается принятая архитектоника составления официально-деловой переписки, по понятным причинам почти исключительно рукописного характера. Соблюдение этических и профессиональных правил и норм диктует специфические особенности синтаксиса и обращения к высшему и низшему должностному составу. При переводе на русский язык, прежде всего, учитывались идиомы и эквиваленты, общепринятые в официально-деловой переписке при максимальной сохранности колорита и особенностей, свойственных оригиналу.
\end{abstract}

